\title{
$\nabla$ Exploring Coverage of Non-communicable Diseases in Newspapers
}

IJCRR
ection: Healthcare
ISI Impact Factor
(2019-20): 1.628
Value (2019): 90.81
SJIF (2020) = 7.893
Copyright@IJCRR

\section{Chitra M Kotian' ${ }^{1}$ Kumar Sumit ${ }^{1}$, Shubha H.S. ${ }^{2}$}

'Prasanna School of Public Health, Manipal Academy of Higher Education, Manipal, Karnataka, India; 'School of Communication, Manipal Academy of Higher Education, Manipal, Karnataka, India.

\section{ABSTRACT}

Introduction: Non-communicable diseases (NCDs) are posing a major public health challenge in all countries globally. The print media, especially newspapers, can play a significant role in sensitizing people about the various risk factors, disease symptoms, available treatments, and recommendations for a healthy lifestyle. This study aimed to analyze the coverage of NCDs in English and Kannada daily newspapers and to understand the perspective of physicians and journalists towards it.

Methods: Content analysis of two newspapers was carried out for assessing the coverage of articles based on NCDs. It was followed by carrying out in-depth interviews with 11 physicians and 11 journalists to understand their perspectives on coverage of NCDs in daily newspapers. Thematic analysis of the in-depth qualitative interviews was done manually to identify codes and categories.

Results: The percentage of the total area occupied by NCD-related news in the daily newspaper was minimal (0.07\%). According to the physicians, the coverage of health in newspapers was insufficient, and the presence of health products advertisements was misleading. The in-depth interviews with journalists revealed barriers in health reporting like difficulty in understanding medical terminologies, lack of insight into topics that need attention, and time constraints.

Conclusions: This study directs attention towards better communication between health professionals and journalists for improved health coverage in newspapers.

Key Words: Content analysis, Health communication, Journalists, Newspapers, Non-communicable diseases, Physicians, qualitative study

\section{INTRODUCTION}

Non-communicable diseases (NCDs) are posing a significant public health challenge. In 2016, they accounted for $71 \%$ of the deaths globally and $61.8 \%$ of India's deaths. ${ }^{1,2}$ Majority of the NCDs are preventable, and the mass media can play a crucial role in creating public awareness. Newspapers are an essential source of daily information and can shape public perceptions regarding major health issues. In India, 407 million people read daily newspapers (2017 Indian Readership Survey report), an $8 \%$ increase compared to the 2014 IRS report. ${ }^{3}$ There is a rise in the circulation of regional newspapers owing to the increasing literacy rates in the rural population.

For public health professionals to channelize mass media to disseminate health awareness information, it is essential to understand print media's functioning and health cover- age status in newspapers. Physicians, as well as journalists, play essential roles in disseminating health communication. However, both groups have different set of views and opinions. There have been limited studies exploring doctors' and journalists' perspectives on health reporting in newspapers, particularly in the Indian subcontinent. The study aimed to understand the newspaper reportage of NCDs by analyzing the coverage and exploring physicians' and journalists' perspectives towards it.

\section{METHODS}

Our qualitative study was conducted in Udupi, Karnataka, India, between January to June 2018. The study was carried out in two phases. The first phase included carrying out a content analysis of two newspapers for assessing the health

\section{Corresponding Author:}

Chitra M Kotian, Prasanna School of Public Health, Manipal Academy of Higher Education, Manipal-576104, India. E-mail: chitrakotian03@gmail.com

ISSN: $2231-2196$ (Print)

Received: 22.08 .2021
ISSN: 0975-5241 (Online)

Revised: 25.09 .2021
Accepted: 16.10 .2021
Published: 03.01.2022 
content in particular to the coverage of articles on noncommunicable diseases. This was followed by carrying out in-depth interviews with 11 physicians and 11 journalists to understand their perspectives on coverage of non-communicable diseases in daily newspapers.

\section{Phase 1 (Content analysis):}

Content analysis of two newspapers, English' Times of India' (TOI) and Kannada' Udayavani' was conducted for issues from 1st October and 31st December 2017 including supplements and health advertisements. A coding sheet was developed for carrying out the content analysis considering the following parameters: day of the week, page no., the section of the newspaper, graphics, no. of images, total area, type of article, and the theme/ topic of the article. The data was entered and analyzed in MS Excel 2016.

\section{Phase 2 (In-depth interviews):}

A total of 11 physicians and 11 journalists were interviewed for the study. Prior appointment was taken from both the physicians and journalists. The interviews with the physicians were carried out at their clinic, and the interviews with the journalists were carried out in their respective offices. The interviews were audio-recorded after obtaining written informed consent from the participants. On an average, the interviews lasted for 30-45 minutes. The interviews were carried out in English and Kannada as per the convenience of the participants. After the interviews, the transcripts of the interviews were prepared, and accordingly, the translation was done. Thematic analysis of the in-depth qualitative interviews was done manually to identify codes and categories.

Ethical approval: The ethical clearance for the study was obtained from the Institutional Ethics

Committee (IEC 794/2017).

\section{RESULTS}

\section{Content analysis results}

The percentage of the total area occupied by NCD related articles between October to December 2017 in TOI was $0.06 \%$ and $0.07 \%$ in Udayavani (Table 1). Out of 680 health-related content published in both the newspapers, 163 were NCD related. Among the 163 articles, 50.92\% (n=83) were articles on NCDs, and $49.07 \%(n=80)$ were NCD related advertisements. Among the 83 articles on NCD, 34 were published in TOI, and 49 were in Udayavani. Table 2 describes the frequency of the different categories of NCD-related news articles printed in these two newspapers. The NCD-related awareness articles were higher in Udayavani due to the weekly health supplement Arogyavani. The English newspaper had more of NCD-based news stories, editorial, feature articles, reports of the journal published research articles as compared to the Kannada newspaper. Advertorials were present in Udayavani.

Figure 1 compares the frequency of NCD-related news articles and advertisements in the TOI and Udayavani. The percentage of NCD-related advertisements in the Kannada newspaper was high as compared to that of the English newspaper. Udayavani provided more news coverage to NCD-related camps and awareness programs and articles on diabetes and chronic respiratory diseases. In contrast, the TOI focused more on articles related to cancer, mental health, and eye-related chronic diseases(Figure 2). Among the NCD-related advertisements $(n=80), 54 \%$ were related to products like pain relief oil, diabetes medication, and $46 \%$ were related to hospital services and healthcare providers. No NCD-related article appeared on the front page of either English or Kannada newspaper.

\section{Qualitative analysis results}

The qualitative analysis was done under two main categories for physicians and journalists: 1) Perceptions on reporting of non-communicable diseases, 2) Suggestions to improve health reporting. The qualitative analysis for the journalists included an additional category of factors affecting health reporting. Findings are reported along with quotes from the participants.

\section{A. Physicians}

\section{Category 1: Perceptions on reporting of non-communi- cable diseases}

\section{Code: Health seeking behaviour}

The majority of the physicians believed that newspapers could play a role in promoting the health-seeking behavior of the people. Especially in rural areas, health articles published in the regional newspapers can be a source of information, increasing the awareness, thereby leading to an increase in screening. "Many times, it has happened that patients walk into our clinic with a newspaper cut out of a health article saying that I think I have the same symptoms which are described here. This is the sign of a very nicely written article where the patient could relate to his symptoms in an article, and he could come to a health professional seeking assistance." (Physician 3)

\section{Code: Insufficient NCD coverage}

The physicians expressed that there was insufficient coverage of lifestyle diseases in the daily newspapers. They felt the weekly health supplement carried out health-related information; however, on other days, there is insufficient health news coverage. "Media have dedicated one day I think to talk with a doctor. However, the highlight is on important 
occasions like World Heart Day and Doctor's Day, but other than that, there is no proper space given for covering the noncommunicable disease." (Physician 4)

\section{Code: Misleading advertisements}

The physicians opined that the presence of a large number of advertisements on NCDs was misleading. Most of the time, the placement of these health-related advertisements was next to the health awareness articles, thereby attracting the readers' attention. Some physicians reported that many patients came to them with complications faced because of these advertised products. The physicians believed that the media should thoroughly regulate the advertisements in the newspapers."People are misguided by these advertisements because the people are fed up with their diseases. They will try to find an easy way to get a cure. Advertisements take advantage by misusing people's emotions and selling stuff that does not have any medical records or proper studies. Some people have got a habit of buying medicines over the counter just by seeing these advertisements." (Physician 5)

\section{Category 2: Suggestions to improve health reporting}

\section{Code: Consulting a physician before publishing}

Most of the physicians felt that the healthcare article should be checked by a medical professional for accuracy and relevance before printing in the newspaper. They felt that, at times, newspaper tends to sensationalize health news to attract the attention of the readers, often leading to fear and panic. "Form a panel with physicians who are genuinely interested and take their help to come out with concrete write up or way of presenting with regards to medical terms." (Physician 6)

\section{Code: Writing easily understandable health articles}

Many of the physicians felt that it is vital to write articles that a layperson can easily understand. Most of the awareness articles that are being written include a lot of technical terms that are difficult for the public to grasp.

\section{Code: Continuity of the health articles}

The physicians also believed that the awareness articles that are published in the newspapers should not be one-time but a series of articles on a particular topic. "Suppose today if they write one article about diabetes, the same article must be continued next week. Sometimes they will write one article and next week they will write another topic, people end up forgetting." (Physician 2)

\section{B. Journalists}

Category 1: Perceptions on reporting of non-communicable diseases

\section{Code: The importance is given to immediacy}

The majority of the journalists believed that newsworthy articles get reported in newspapers. Thus, health awareness articles were often not prioritized. "When it comes to news, health awareness articles cannot attract readers, like there are days like diabetes day that is fine but if an article on five people affected by malaria, there will be many readers for that" (Journalist 4)

\section{Code: News articles catered as per rural/urban readers}

The English newspaper carried more articles on cancer, mental health, and chronic disease. The journalists explained the difference in the audience of newspapers. The English newspaper usually targets readers in the city area, so it publishes articles according to the needs of the urban readers. Meanwhile, the Kannada newspapers target the rural population, hence news coverage on health camps was beneficial as it could make people aware of it. "English newspaper people read it for knowledge, leisure, and they don't go often for such camps, they usually directly go to the doctor. Kannada newspapers write about camps with regional readers in mind. People from rural areas who get health checked for the first time generally go for the free camps reading from Kannada newspapers.” (Journalist 6)

\section{Code: Advertisements are a source of revenue and ca-} tered to readers

The majority of the journalists opined that advertisements are one of the significant sources of revenue for the newspaper. The differences in the number of advertisements were because it is expensive to print advertisements in an English newspaper as compared to the regional newspaper.

\section{Category 2: Factors affecting health reporting for jour- nalists}

\section{Code: Difficulty in understanding medical terminologies}

Many journalists said that the most significant barrier while reporting health news was the difficulty in understanding various medical terminologies and later simplifying and writing them in newspapers.

\section{Code: Lack of insight into topics that need attention}

The journalists opined that although they are interested in covering health issues, they lack insight into the health issues that need attention. The journalists felt that with guidance on topics that needs to be covered, they could report health issues better.

\section{Code: Time and space constraints in newspapers}

The journalists opined that daily newspapers are time-bounded, unlike a periodical, and found it challenging to devote time 
to health news. Space constraints in the newspaper were another restricting factor. The reporters usually must go by the space allotted to them to cover health issues. The journalists felt that the newspaper should allocate a health column or designated space for carrying out health stories.

\section{Code: Interest/Motivation of journalists}

Covering health issues depends on the interest levels of the journalist. Journalists with a science background had more interest in covering health news than a journalist without a science background who felt covering health news was similar to crime, politics, or sports.

\section{Category 3: Suggestions to improve health reporting}

\section{Code: Need for better health reporting training}

Most of the journalists believed that they lacked the skills needed to write health articles and there was a need for a training workshop. They felt it was essential that the workshop be skill-based. "Those who give training should have an idea of how newspapers and media works; otherwise, it is of no use. They only think from their perspective." (Journalist 2)

\section{Code: Sharing health research findings through media}

Few journalists opined that there was a need for printing more Indian based research in the newspaper. "Health-based research articles always get published in research journals, but the findings are not conveyed to the mass. So, if it comes to the newspaper, then it is more interesting. People will come to know what is happening." (Journalist 5)

\section{Code: Communication between the medical sector and media}

The most critical need was to bridge the gap in communication between physicians and journalists. Few journalists did often interact and clarify their doubts with doctors. However, for others, there was still a lack of interaction with the medical fraternity. The journalists felt that there was difficulty in accessing information from them.

Figure 3 summarizes the key findings of physicians and journalists' perceptions on coverage of non-communicable diseases in newspapers.

\section{DISCUSSION}

To the best of our knowledge, this is the first Indian study of its kind to analyze the coverage of health, especially NCDs and explore the perspectives of journalists and physicians on it. Content analysis of TOI and Udayavani revealed that the percentage of the total area occupied by NCD-related articles was minimal $(0.07 \%)$. The percentage of NCD-related news articles in English newspapers was higher as compared to the percentage of NCD-related advertisements. However, it was the opposite in the case of the Kannada newspaper, whereby the percentage of NCD-related advertisements was higher as compared to news articles. Similar findings were seen in the study by Gupta A, Sinha AK. ${ }^{4}$ They reported that healthrelated news ranked first followed by advertisements in the English newspaper, whereas in the Hindi newspaper advertisements of health-related products and health care providers were more as compared to health articles. In our study, we observed that there was no NCD-related news article that appeared on the front page of the newspaper of either English or Kannada newspaper for three months. Maheshwar M and Rao $\mathrm{D}^{5}$ in their study of quantitative analysis about nutrition and health messages during February 2010 in English (The Hindu) and Telugu (Eenadu) newspapers also did not find any nutrition-related article on the front page of either of the newspaper.

According to the thematic analysis of in-depth interviews with the physicians, it found that the physicians believed that newspapers could play an essential role in increasing awareness regarding NCDs. They opined that health issues could be addressed through newspapers and brought to the attention of the readers; however, health is not given much prominence in the newspaper.

The factors affecting health reporting in the newspapers identified by the journalists in this study included difficulty understanding medical terminologies, lack of insight into topics that need attention, time and space constraints, interest/motivation of journalists, getting news verified from physicians. Similar findings were noted in a Norwegian study by Larsson et al. ${ }^{6}$ and a study conducted by Ashoorkhani $\mathrm{M}$ et al. ${ }^{7}$ in Iran. A study by Melinda Voss ${ }^{8}$ among health reporters in five Midwestern states revealed that one-third of the participants found understanding and reporting key health topics to be difficult, and $73 \%$ reported that health training was needed. Similarly, a cross-sectional study conducted in Isfahan, Iran, revealed that $97 \%$ of the journalists interviewed were eager to participate in specialized health education for health news reporting. ${ }^{9}$ Our study supports this finding as the majority of the journalists felt the need for training or workshop for better health reporting.

In our study both the physicians and journalists believed that newspapers could help to improve health awareness among the people. Both groups felt that the coverage of health in the newspapers was less. The physicians felt that efforts are needed to improve the quality of health articles published in newspapers. The journalists felt the need for the guidance and feedback from physicians for writing health-related articles better. Thus, there is clearly a need for coordination between physicians and journalists to improve health reporting in daily newspapers. 


\section{CONCLUSION}

Findings from our study reveal that the overall space occupied by health news and articles on NCDs in daily newspapers was less. Kannada newspaper carried more NCD-related advertisements in the newspaper as compared to the English newspaper. There was also a difference in the specific NCD topics covered by both newspapers. Qualitative interviews with the physicians revealed that the overall space and coverage for NCDs were insufficient, and the presence of NCDrelated advertisements was misleading. The interviews with journalists showed that the priority was given more towards news that attracted the readers' attention, and most of the time, the articles were catered as per the rural/urban readers. Journalists also felt the need for guidance of the physicians for writing better health articles. Thereby, we conclude that there is a communication gap between physicians and journalists that need to be bridged, a focus that has not been highlighted in prior studies in public health and media studies.

Limitation of the study: Our study's limitations were that the content analysis was done for only two newspapers and a shorter duration.

\section{ACKNOWLEDGEMENT}

The authors wish to acknowledge the contributions of Dr. Prakash Narayan, Associate professor, Prasanna School of Public Health

\section{Source of Funding: None}

Conflict of interest: Authors have no conflict of interest.

\section{Authors' Contribution:}

All authors (CMK, KS, SHS) contributed to the study conception and design. The literature review, data collection and analysis were performed by CMK. The first draft of the manuscript was written by CMK. All authors (CMK, KS, SHS) were involved in the editing and review of the final manuscript. All authors read and approved the final manuscript.

\section{REFERENCES}

1. World Health Organization. WHO | NCD mortality and morbidity. 2018. Available from: https://www.who.int/gho/ncd/mortality_morbidity/en/

2. Dandona L, Dandona R, Kumar GA, Shukla DK, Paul VK, Balakrishnan $\mathrm{K}$ et al. Nations within a nation: variations in epidemiological transition across the states of India, 1990-2016 in the Global Burden of Disease Study. Lancet. 2017 Dec 2 ;390(10111):2437-60. Available from: http://www.ncbi.nlm.nih. gov/pubmed/29150201

3. Indian readership survey. IRS 2017 KEY TRENDS. 2018. Available from: http://mruc.net/uploads/posts/a27e6e912eedeab9ef944cc3315fba15.pdf

4. Gupta A, Sinha AK. Health Coverage in Mass Media: A Content Analysis. J Commun. 2010;1(1):19-25. Available from: https:// pdfs.semanticscholar.org/98bd/13e0acb9fa6b0470a78504e5a3f a18a7a6f2.pdf

5. Maheshwar M, Rao DR. Quantitative Analysis of Nutrition and Health Messages in Indian Print Media. Public Heal Res. 2012;2012(2):28-31. Available from: http://journal.sapub.org/ phr

6. Larsson A, Oxman AD, Carling C, Herrin J. Medical messages in the media--barriers and solutions to improving medical journalism. Health Expect. 2003 Dec;6(4):323-31. Available from: http://www.ncbi.nlm.nih.gov/pubmed/15040794

7. Ashoorkhani M, Gholami J, Maleki K, Nedjat S, Mortazavi J, Majdzadeh R. Quality of health news disseminated in the print media in developing countries: a case study in Iran. BMC Public Health. 2012 Dec 9;12(1):627. Available from: http://www.ncbi. nlm.nih.gov/pubmed/22873836

8. Voss M. Checking the pulse: Midwestern reporters' opinions on their ability to report health care news. Am J Public Health. 2002 Jul;92(7):1158-60. Available from: http://www.ncbi.nlm. nih.gov/pubmed/12084701

9. Keshvari M, Yamani N, Adibi P, Shahnazi H. Health journalism: Health reporting status and challenges. Iran J Nurs Midwifery Res. 2018;23(1):14. Available from: http://www.ncbi.nlm.nih. gov/pubmed/29344040

Table 1: Percentage of the total area occupied by NCD related articles in TOI and Udayavani newspaper from October $1^{\text {st }}, 2017$ to December $31^{\text {st }}, 2017$

\begin{tabular}{lcccc} 
Newspaper & $\begin{array}{c}\text { Total number } \\
\text { of pages }\end{array}$ & Total area $\left(\mathrm{cm}^{2}\right)$ & $\begin{array}{c}\text { The total area occupied by } \\
\text { NCD related articles }\left(\mathrm{cm}^{2}\right)\end{array}$ & $\begin{array}{c}\text { Percentage of the total area oc- } \\
\text { cupied by NCD related articles }\end{array}$ \\
TOI & 5755 & $1,11,98,079$ & 6759.45 & $0.06 \%$ \\
Udayavani & 10806 & $1,96,44,227.4$ & 14049.25 & $0.07 \%$ \\
Total & 16561 & $3,08,42,306.4$ & 20808.7 & $0.07 \%$ \\
\hline
\end{tabular}

Table 2: Frequency of different categories of NCD related news articles in TOI and Udayavani newspaper from October 1st, 2017 to December 31st, 2017

\begin{tabular}{lcccccc} 
Newspaper & News stories & $\begin{array}{c}\text { Awareness } \\
\text { articles }\end{array}$ & $\begin{array}{c}\text { Report of the } \\
\text { published study }\end{array}$ & Editorial & Feature & Advertorial \\
TOI & $58.82 \%$ & $14.70 \%$ & $17.64 \%$ & $2.94 \%$ & $5.88 \%$ & $0.00 \%$ \\
Udayavani & $48.97 \%$ & $46.93 \%$ & $0.00 \%$ & $0.00 \%$ & $0.00 \%$ & $4.08 \%$ \\
\hline
\end{tabular}




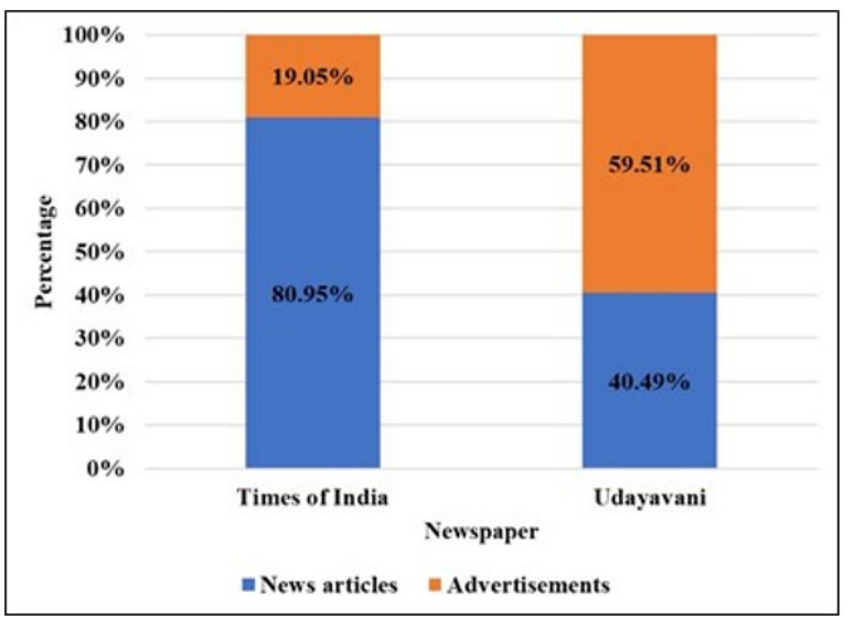

Figure 1: Frequency of NCD related news articles and advertisements in the TOI and Udayavani newspaper between October 1st, 2017 to December 31st, 2017.

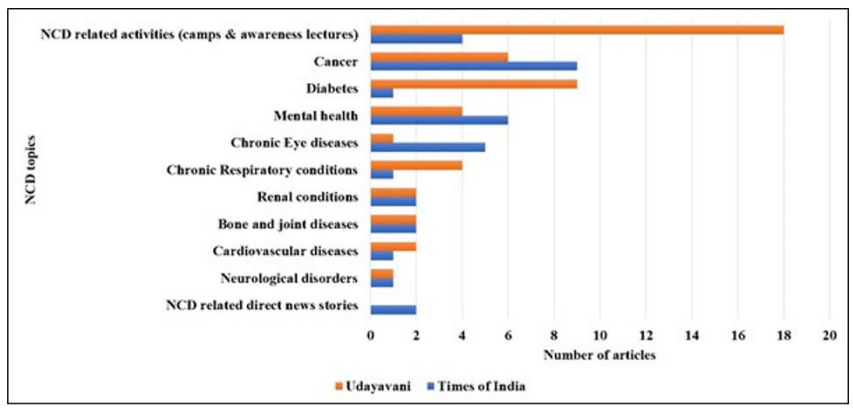

Figure 2: Comparison of NCD topics in TOI and Udayavani newspaper between October 1st, 2017 to December 31st, 2017.

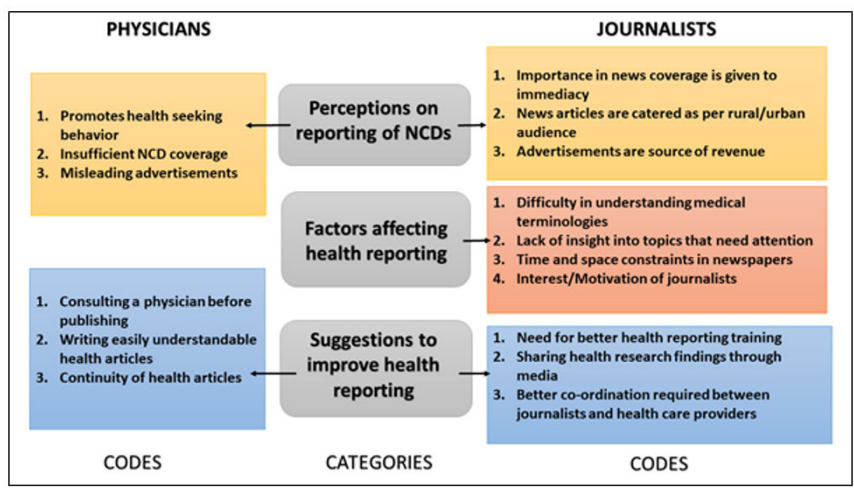

Figure 3: Summary of key findings of physician and journalist's perceptions on coverage of non-communicable diseases in newspapers. 